\title{
Design and evaluation of a highly-efficient miniature mixing system
}

\begin{abstract}
Mixing technologies are used widely in chemical and biological fields, and extensive research has been conducted to develop mixers for different levels of mixing rates and volumes. This paper reports a miniature mixing system constructed from a circular mixer and two miniature piezoelectric pumps. This system was designed to be easy to assemble and disposable. The circular mixer was based on a serpentine channel with a slit to perform the mixing process. The influence of different mixing chamber designs on the mixing efficiency of the system under a $12 \mathrm{ml} / \mathrm{min}$ flow rate was studied by simulation and experimental methods. The mixing process could be completed in 9 seconds using a $3 \mathrm{~mm}$ corner space, which shows the significance of the mixer. Both simulation and experimental results are presented and discussed, and the design criteria for an optimal mixer design are addressed as well.
\end{abstract}

Volume 4 Issue I - 2018

\author{
Hsiao-Kan Ma, Rong-Huei Chen, Meng-Syuan \\ Dai, Sih-Ci Liou \\ Department of Mechanical Engineering, National Taiwan \\ University, Taiwan
}

Correspondence: Rong-Huei Chen, National Taiwan University, Department of Mechanical Engineering, No I, Sec 4, Roosevelt Rd, Taipei 10617, Taiwan (ROC), Fax +886-223632644, Tel +886-2-3366-3366, Email d02522022@ntu.edu.tw

Received: February 01, 2018 | Published: February 12, 2018

Keywords: mixer, miniature mixing system, mixing chamber structure

\section{Introduction}

With the increasing need for molecular reactions with small liquid volume in biomedical and chemical analyses, miniature mixers have captured considerable attention. Due to the nature of laminar flow in a millimeter-size and blow flow channel, mixing, or the molecular mass transfer in miniature mixers is usually dominated by molecular diffusion. The long diffusion time and mixing distance make rapid mixing unachievable. To address low mixing efficiency, various active or passive micro mixers have been proposed and examined. ${ }^{1-10}$ Miniature mixers can be divided into two types: active and passive. Active mixers are equipped with various driving sources based on different mechanisms to create fluctuations within the fluid to achieve high mixing efficiency. ${ }^{11-20}$ For example; Moctar et al. ${ }^{21}$ developed a mixer using electro-hydrodynamic force (EHD) to drive two types of fluids with different electrical properties. The two fluids were brought into contact in a channel and were optimized by controlling the Reynold number (Re) at 0.0174 . Thus, mixing could be achieved in less than $0.1 \mathrm{sec}$ within a short distance. Ahmed et al. ${ }^{22}$ studied an acoustically driven mixer with an air bubble trapped inside the mixing channel. The air-liquid interface could be excited to resonance by acoustic excitation to induce streaming for mixing; it took only a few milliseconds to complete the mixing process. Liu et al. studied a pulsed mixing method based on a Y-shaped micromixer driven by two piezoelectric micro-pumps. Using two out-of-phase sinusoidal waves, the contact area between two solutions could be increased. They successfully used this device to synthesize gold nanoparticles using $\mathrm{HAuCl}_{4}$ and $\mathrm{Na}_{3} \mathrm{C}_{6} \mathrm{H}_{5} \mathrm{O}_{7}$ solutions. ${ }^{23} \mathrm{~A}$ good synthesis was achieved with a Y-entrance angle of 60 degrees and flow rate of $4 \mathrm{ml} /$ min. Passive mixers usually utilize molecular diffusion and chaotic advection.

The liquid flowing in traditional T-shaped and Y-shaped mixers is basically laminar flow, leading to long mixing distance and time due to weak molecular diffusion and strong advection $(\mathrm{Pe}>>1)$. To enhance transverse advection, passive mixers with various complicated geometries have been developed, including the tesla micromixer, ${ }^{24}$ the zigzag micromixer, ${ }^{25}$ the split-and-recombine (SAR) micromixer, ${ }^{26}$ the slanted groove micromixer, and the curved channel micromixer. ${ }^{27-29}$
Schönfeld et al. ${ }^{30} \& \mathrm{Li}$ et al. ${ }^{31}$ designed and implemented different SAR micromixers. The special sub-channels in this type of mixer split the flow stream and destroy the laminar flow characteristics within the stream to increase the tendency of chaotic advection. Lynn and Dandy numerically studied a micromixer embedded with microgrooves and described the dependence of mixing efficiency on the channel aspect ratio, the groove depth ratio, and the ridge length. ${ }^{32}$ By changing the geometric parameters of the mixing channel, the variation of the transverse advection flow can be as large as $50 \%$. Nguyen ${ }^{33}$ \& Jeong $^{34}$ gave good reviews of mixer design and applications; their studies suggested that the geometric parameters and the flow rates are essential to the design of good mixers. In this study, a miniature mixing system is developed by combining a passive mixing chamber and two miniature pumps like that reported in our previous studies. ${ }^{35} \mathrm{~A}$ circular-shaped mixing chamber was adopted for easy assembly, with different mixing channels designed within the chamber to investigate the optimal mixing effectiveness. A simulation was conducted first to study the feasibility of the mixing system based on a serpentine channel structure and different corner space design within the flow channel. Experimental studies were conducted to verify the design. Finally, the method to optimize this design is discussed.

\section{Development of piezoelectric-driven mixing system}

\section{Design of miniature mixer chamber}

Figure 1 shows the configuration of the miniature mixer. The mixer chamber consists of a chamber body and a cover made of PMMA, an O-ring, and three silicone check valves. The PMMA device was fabricated by computer-numerical-controlled (CNC) machining. The dimensions of the mixer chamber are $50 \mathrm{~mm}$ by $50 \mathrm{~mm}$ by $12 \mathrm{~mm}$. Check valves were made by machine punching from a $300-\mu \mathrm{m}$-thick silicone sheet. A commercially available 3-mm-thick silicone O-ring with an inner diameter of $36 \mathrm{~mm}$ was chosen to create an airtight seal between the cover and the mixer chamber. The chamber has an inner diameter of $34 \mathrm{~mm}$ and a chamber depth $(d)$ of $0.45 \mathrm{~mm}$. To explore the optimization directions of mixing efficiency, a series of serpentine channels and a slit were designed and fabricated. Figure 2 shows the 
proposed chamber structure designs. Figure 2A illustrates the top view of the mixing system. Figure $2 \mathrm{~B}$ shows the top view and the cross-sectional view of the mixing chamber without inner structures. Figure $2 \mathrm{C}$ shows the top view and the cross-sectional view of the mixing chamber with flow channel design. Two design parameters, the channel width $w$ and the corner space $s$ at the first two turning corners within the flow channel, are specified in Figure 2D. The selection of the corner space dimension followed the study of Pradeep et al. ${ }^{36}$ According to their findings, widening (double) or narrowing (half) of the channel width at the turning point can enhance mixing efficiency, while maintaining the same channel width at the turning point yields less efficient mixing. As the channel width $w$ was fixed at $1.5 \mathrm{~mm}$, the corner space $s$ was set at $0.75 \mathrm{~mm}$ and $3 \mathrm{~mm}$ to investigate the influence of corner space dimensions on the mixing efficiency. A crossline $L$ also was defined at the outlet of the mixing chamber in Figure 2D for the monitoring of the fluid concentration at the outlet to evaluate mixing efficiency. In addition, along the flow channel, 11 checkpoints were chosen to monitor the fluid concentration during the mixing process, as shown in Figure 2E.

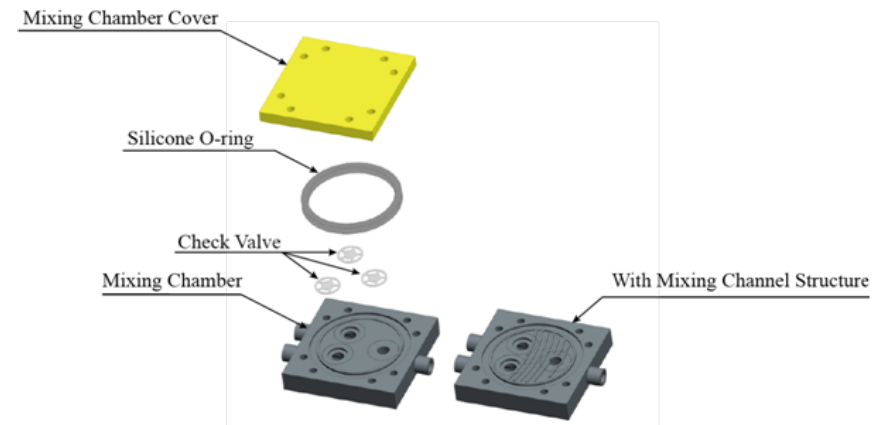

Figure I Illustrations of the mixing chamber assembly.

\section{Experimental setup}

Figure 3 shows the experimental setup of the mixer system using the proposed mixer with the miniature piezoelectric pumps developed earlier by the authors. ${ }^{35}$ Two miniature pumps were driven by a $15 \mathrm{~Hz}$, $60 \mathrm{~V}_{\mathrm{pp}}$ sinusoidal driving voltage (Chroma 61501 Programmable AC Source) to yield a $12 \mathrm{ml} / \mathrm{min}$ flow rate at the outlet of the mixing chamber. Two working fluids (water) dyed red and blue were pumped into the mixing chamber by the two miniature pumps. The three pipes were connected to the inlets, and the outlet of the mixer was horizontally leveled to create zero backpressure in the mixing system. A Sony $\alpha 7$ high-speed camera was fixed on top of the transparent mixing chamber to capture the mixing process. The mixing chamber and miniature pumps were assembled in air, and the mixing chamber first was filled with the red fluid driven by one miniature pump before sending the blue fluid from the second pump to initiate the mixing process. For consistency, the same setup was applied to both simulations and experiments. All mixing experiments with different mixing chamber structure designs were conducted under the same conditions.

\section{Numerical simulation}

Finite element analysis: The 3D finite element model of the mixer was built using commercial COMSOL Multiphysics ${ }^{\circledR}$ software. According to Sayah et al., ${ }^{37}$ a two-step analysis can be used to simulate the mixing mechanism. The first step is to obtain the flow velocity vector field via the continuity equation Eq. (1) and NavierStokes equation Eq. (2):

$$
\nabla \cdot u=0
$$

$$
\rho \frac{\partial u}{\partial t}+\rho(u \cdot \nabla) u=-\nabla p+\mu \nabla^{2} u
$$

Where $\rho$ is the fluid density, $u$ is the flow velocity vector, $\mu$ is the fluid viscosity, and $p$ is the pressure. To determine the spatial fluid concentration under a stationary condition, the velocity field is saved and applied in the convective mass-transport part of the convectiondiffusion equation:

$$
\frac{\partial C}{\partial t}+(u \cdot \nabla) C=D \nabla^{2} C
$$

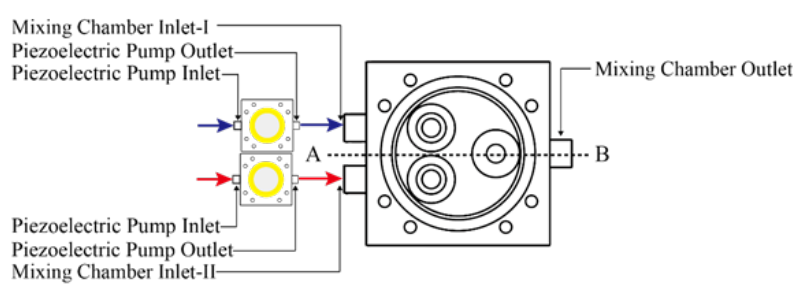

Piezoelectric Pump Outle

(A)

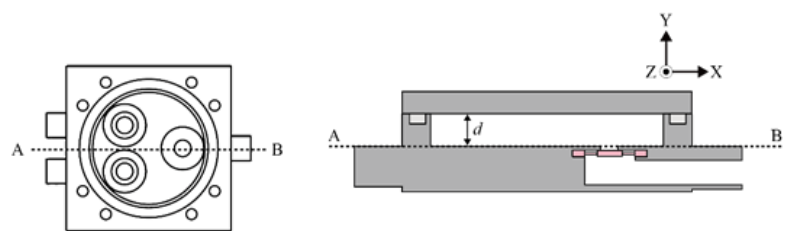

(B)
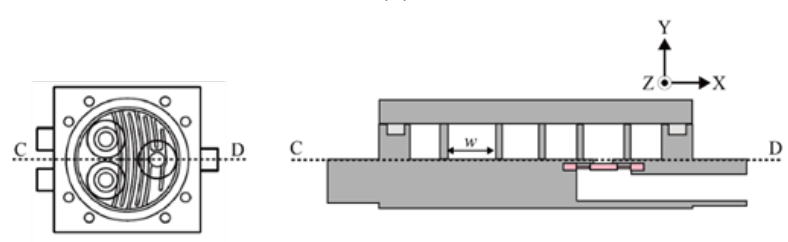

(C)

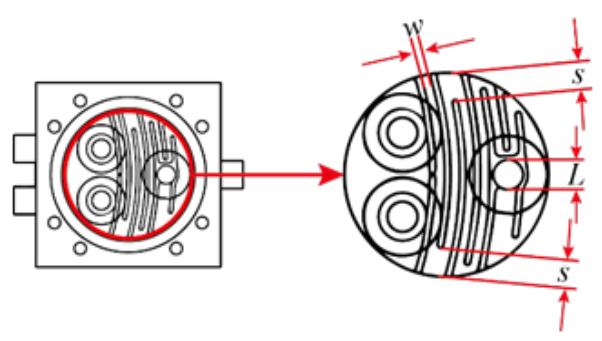

(D)
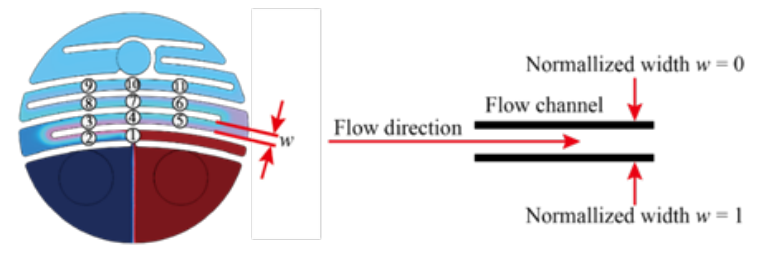

(E)

Figure 2 Illustrations of the mixing chamber structure.

(A) Top-view of mixing system.

(B) Cross-section view along the A-B line without flow channel design.

(C) Cross-section view along the C-D line with flow channel design.

(D) Definition of the flow channel width $w$, corner space $s$, and crossline of $L$.

(E) Definition of the normalized width along $w$. 
Where $D$ and $C$ denote the diffusion coefficient and the concentration of the species, respectively. The boundary conditions were given as follows: (1) non-slip boundary condition on the channel wall, (2) half pulse flow with sinusoidal wave with $15 \mathrm{~Hz}$, input introduced at each inlet, (3) laminar flow, (4) average flow velocity of $0.02 \mathrm{~m} / \mathrm{s}$, corresponding to $6 \mathrm{ml} / \mathrm{min}$ volume flow rate for each inlet, (5) zero outlet pressure, (6) total number of meshes set at 994,227, supported by the mesh convergence analysis shown in Figure 4, and (7) normalized concentration of $0 \mathrm{~mol} / \mathrm{m}^{3}$ and $1 \mathrm{~mol} / \mathrm{m}^{3}$ set for fluids at Inlet-I (navy blue color) and Inlet-II (dark red color), respectively. The ideal mixing result should be reaching the $0.5 \mathrm{~mol} / \mathrm{m}^{3}$ concentration at the outlet. Diluted water solutions with color dyes were chosen as the working fluids. The dynamic viscosity and mass density of water at room temperature $\left(25^{\circ} \mathrm{C}\right)$ were $1 \times 10^{-3} \mathrm{~Pa} \cdot \mathrm{s}$ and $998 \mathrm{~kg} / \mathrm{m}^{3}$, respectively. The diffusion coefficient of the dye in water was first experimentally determined to be $D=1.537 \times 10-9 \mathrm{~m}^{2} / \mathrm{s}$ (following. ${ }^{33}$ ) before it was used in the simulation in this study.

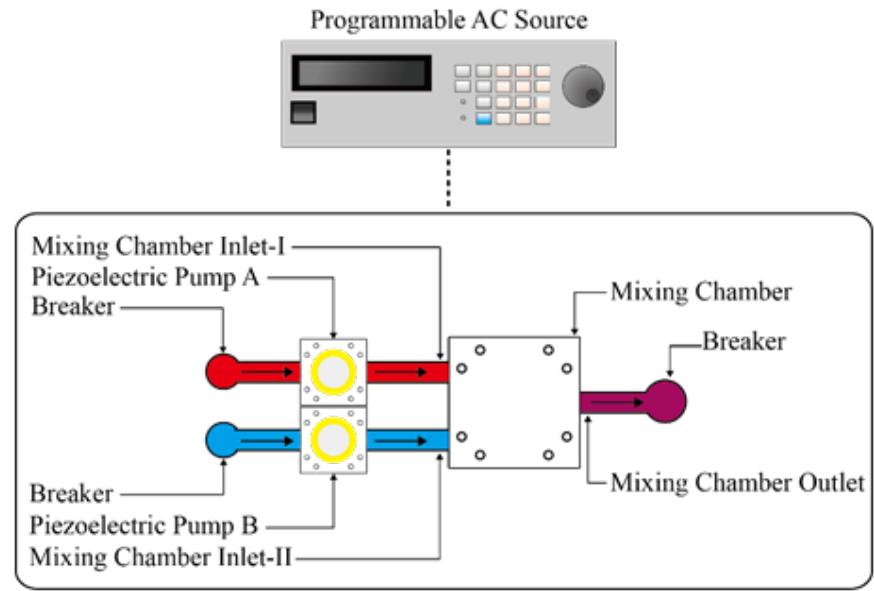

Figure 3 An illustration of the experimental setup.

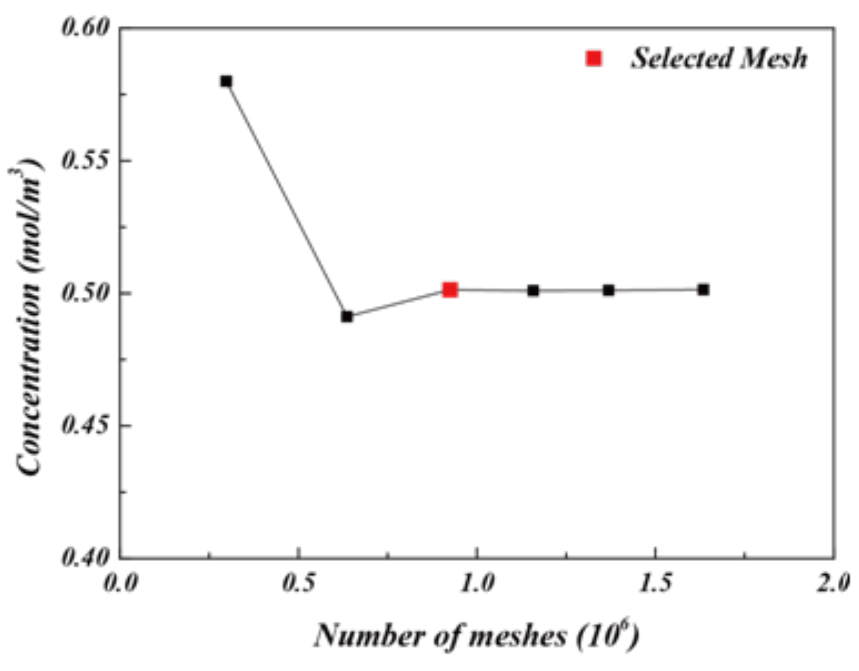

Figure 4 Mesh convergence analysis of the fluid concentration at the outlet.

\section{Mixing performance}

To describe the mixing performance along the mixing channel quantitatively and to compare the simulated and experimental results, top-view images of the fluid concentration profile of the mixing chambers were taken for both simulations and experiments. Following Ansari et al. ${ }^{38} \&$ Afzal et al. ${ }^{39}$ the fluid concentration at any given point within the flow channel can be converted from the hue angle level $h_{i}$ of the fluid color at each point/pixel on the top-view image using MATLAB. The hue angle level $h_{i}$ was defined between 0 and 1 , with red assigned as 1 and blue assigned as 0 . The color of the ideal mixed fluid should give a hue angle level of 0.5 , corresponding to the fluid concentration of $0.5 \mathrm{~mol} / \mathrm{m}^{3}$. The mixing performance can be evaluated by the mixing indices $M P$ at the 11 checkpoints along the flow channel (defined in Section 2.1), which is defined as:

$$
M P=\left[1-\sqrt{\frac{\sigma_{i}^{2}}{\sigma_{\max }^{2}}}\right] \times 100 \%
$$

Where $\sigma_{i}$ is the standard deviation of the converted concentration at checkpoint $i$ and $\sigma_{\max }$ is the largest among $11 \sigma_{i}$. A higher $M P$ value indicates a more homogeneously distributed concentration and better mixing performance from $0(0 \%$, not mixing) to $1(100 \%$, fully mixed).

\section{Results and discussion}

\section{Determination of the diffusion coefficient of the dyed fluid}

In this study, the diffusion coefficient was determined first for simulation studies. A T-shaped device with a $15 \mathrm{~mm} \times 2 \mathrm{~mm} \times$ $0.5 \mathrm{~mm}$ flow channel connected to two entries was designed for this evaluation, as shown in Fig. 5. As the two dyed water solutions were considered highly diluted with both concentrations set at the same value of $5 \times 10^{-4}$, the diffusion coefficients of the two dyed fluids can be assumed equal, regardless of the sizes of the dye molecules. Following the studies by Nguyen et al. ${ }^{33,34}$ the concentration change along the $\mathrm{y}$-axis perpendicular to the flow direction (x-axis) can determine the diffusion coefficient using the following equation. ${ }^{3 .}$

$$
c^{*}\left(x^{*}, y^{*}\right)=0.5+\frac{2}{\pi} \sum_{n=1}^{\infty} \frac{\sin \alpha \pi n}{n} \cos \left(n \pi y^{*}\right) \times \exp \left(-\frac{2 n^{2} \pi^{2}}{P e+\sqrt{P e^{2}+4 n^{2} \pi^{2}}} x^{*}\right)
$$

where $c^{*}$ is the dimensionless concentration distribution in the tube, $x^{*}=x / W, y^{*}=y / W$, are dimensionless coordinates with tube width $w=2 \mathrm{~mm}, P e=U W / D$ is the Péclet number, and $D$ is the target diffusion coefficient of the dyed fluid. The distribution of fluid concentration along the y direction was determined by the quantitative analysis described in Section 2.2 and is depicted by solid dots in Figure 6. For a given $x^{*}$, equation ${ }^{33}$ was used to fit concentration distribution along $y^{*}$ to yield the diffusion coefficient $D$ under the best fit. Three $x *$ were chosen: $x^{*}=2.25, x^{*}=3.25, x^{*}=5.25$, to give three $D$ values: $1.502 \times 10^{-}$ ${ }^{9} \mathrm{~m}^{2} / \mathrm{s}, 1.543 \times 10^{-9} \mathrm{~m}^{2} / \mathrm{s}$, and $1.567 \times 10^{-9} \mathrm{~m}^{2} / \mathrm{s}$, respectively, as shown in Figure $7 \mathrm{~A}-7 \mathrm{C}$. The average diffusion coefficient was then $1.537 \times 10^{-}$ ${ }^{9} \mathrm{~m}^{2} / \mathrm{s}$, with $1.5 \%$ variation. This diffusion coefficient $D=1.537 \times 10^{-}$ ${ }^{9} \mathrm{~m}^{2} / \mathrm{s}$ was used for the following simulation studies.

\section{Simulation results}

Mixing performance with and without flow channel structures: Figure 7 shows the simulation results of mixing chambers with and without flow channel structures. In Figure 7A, the two fluids flow directly towards the outlet of the mixing chamber in a chamber without mixing channels, resulting in limited time for contact and inducing incomplete mixing. In contrast, by deploying flow channels within the mixing chamber, a clear improvement can be seen, as the measured concentration was close to $0.5 \mathrm{~mol} / \mathrm{m}^{3}$ at exit, as shown in Figure $7 \mathrm{~B}$ 
\& Figure 7C. To further examine the improved mixing performance, the fluid concentrations at the outlet were compared in Figure 8 for chambers without Figure 7A and with flow channel structure along the crossline $L$ as shown in Figure 2. One can see that, for the mixing chamber without flow channel structure, the concentration distribution along $L$ is $1.0 \mathrm{~mol} / \mathrm{m}^{3}$ and $0.0 \mathrm{~mol} / \mathrm{m}^{3}$ at the two ends with only minimal mixing in the middle of the outlet, as shown by the steep slope change in Figure 7A. From Figure 7C, for the mixing chamber with corner space $s=3 \mathrm{~mm}$, the concentration distribution along $L$ falls uniformly at $0.5 \mathrm{~mol} / \mathrm{m}^{3}$. The introduction of flow channels within the mixing chamber increases the contact time between the two fluids and results in satisfactory mixing.
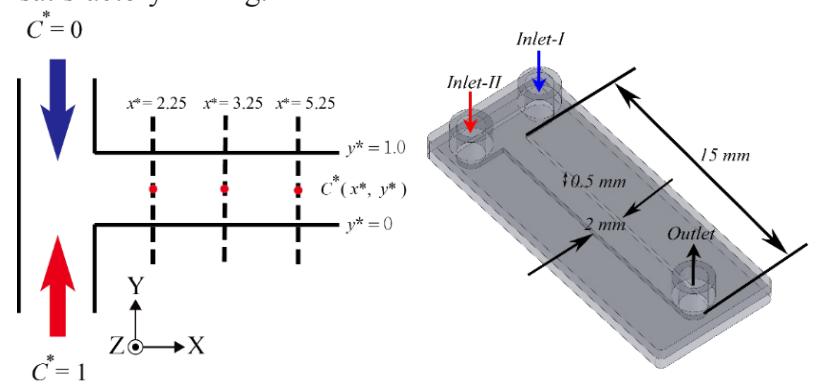

Figure 5 Determination of the diffusion coefficient using a T-shaped channel at different $x^{*}$

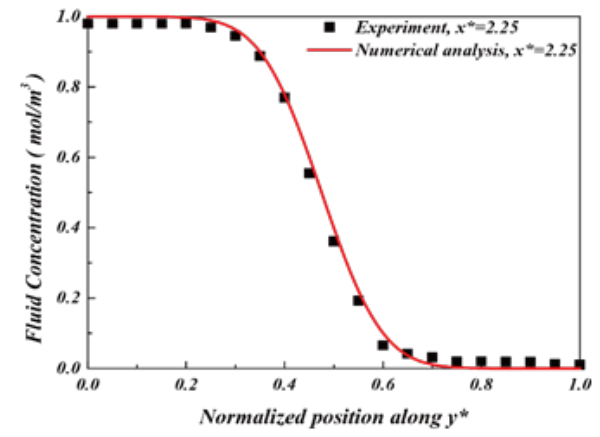

(A)

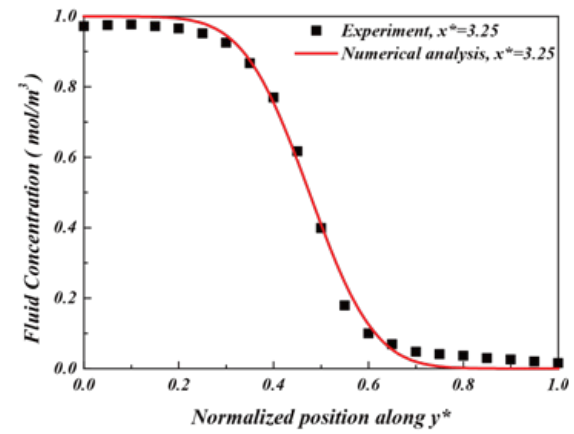

(B)
Influence of corner space design within flow channel on mixing efficiency: Two different corner space designs were studied in the flow channel structure. They are $s=0.75 \mathrm{~mm}$ and $s=3 \mathrm{~mm}$, as shown in Figure 7B \& Figure 7C. The concentration distributions shown in Figure 7B \& Figure 7C suggest that the flow channel structure with $s=3 \mathrm{~mm}$ had better mixing performance than the one with $s=0.75$ $\mathrm{mm}$. This result was confirmed in Figure 9, as the fluid concentration distribution along $\mathrm{L}$ at the outlet for $s=3 \mathrm{~mm}$ falls perfectly at $0.5 \mathrm{~mol} /$ $\mathrm{m}^{3}$. The increased corner space creates an expanded channel width, thereby increasing the distance among fluid molecules. It gives more opportunities for molecules to diffuse through laminar flow layers, as discussed by Pradeep et al. ${ }^{36}$ To further investigate the mixing progress between two fluids, the fluid concentrations were calculated using MATLAB to quantitatively analyze the concentration along the flow channel. Figure 10 shows the fluid concentrations at the 11 checkpoints along the flow channel towards the outlet Figure 2D. Figure 10A-10D show the concentration profile of the flow channels with $s=0.75 \mathrm{~mm}$ and $s=3 \mathrm{~mm}$ corner space. In Figure 10C \& Figure $10 \mathrm{D}$, for $s=3 \mathrm{~mm}$, a clear improvement of fluid concentration towards $0.5 \mathrm{~mol} / \mathrm{m}^{3}$ can be seen. A concentration profile near $0.5 \mathrm{~mol} / \mathrm{m}^{3}$ at the outlet suggests that the channel design was sufficient for mixing. In summary, a chamber structure with serpentine channel design and corner space $s=3 \mathrm{~mm}$ was shown to provide optimal mixing performance in this study.

Figure 6 Concentration measurement within T- shaped channel: (a) $x^{*=2.25}$ (b) $x^{*=3.25}$, (c) $x^{*=}=5.2$

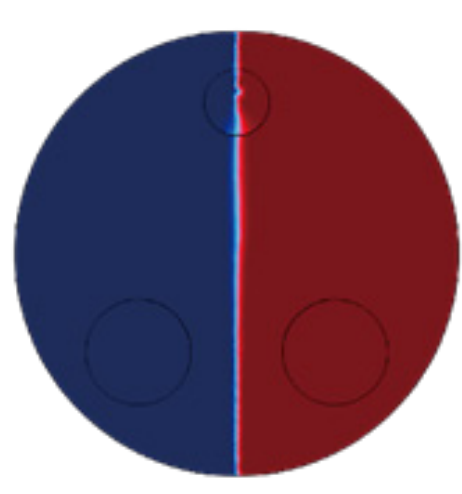

(A) without structure

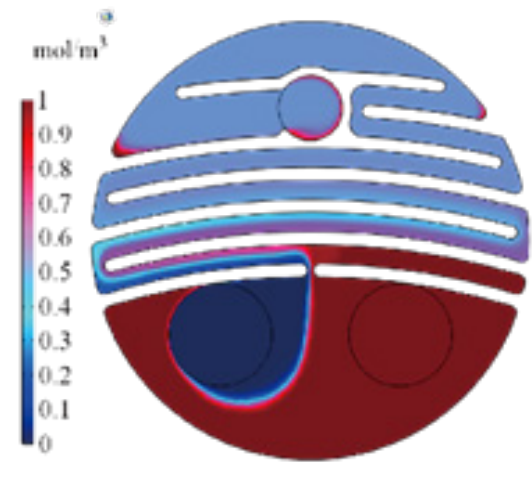

(B) $s=0.75 \mathrm{~mm}$

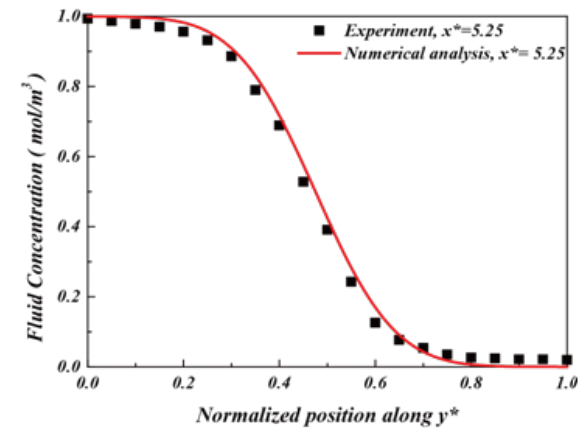

(C)

Figure 7 Simulation results of three mixing chambers: $(A)$ without flow channel, (B) with flow channel $(s=0.75 \mathrm{~mm}),(C)$ with flow channel $(s=3 \mathrm{~mm})$.

\section{Experimental evaluation}

Comparison of the simulated and experimental result performance of fluid mixing at the outlet: To confirm the simulation results, mixer chambers with different interior structures, as shown in Figure 7A-
$7 \mathrm{C}$, were fabricated and studied. The corresponding mixing results are shown in Figure 11A-11C. The fluid concentration at the outlet along $L$ (defined in Figure $2 \mathrm{C}$ was measured and is shown in Figure 12. From Figure 12A-12C, one can see that the mixing chamber without flow channel design had minimal mixing at the outlet. The mixing 
chamber with flow channel and corner space $s=3 \mathrm{~mm}$ gave the best mixing result, and a concentration distribution range from $0.49 \mathrm{~mol} / \mathrm{m}^{3}$ to $0.53 \mathrm{~mol} / \mathrm{m}^{3}$ was achieved. The average concentration was $0.50 \mathrm{~mol} /$ $\mathrm{m}^{3}$ with a standard deviation of $0.007 \mathrm{~mol} / \mathrm{m}^{3}$. The design with corner space $s=0.75 \mathrm{~mm}$ generated concentration distribution ranging from $0.52 \mathrm{~mol} / \mathrm{m}^{3}$ to $0.63 \mathrm{~mol} / \mathrm{m}^{3}$. The average concentration was $0.60 \mathrm{~mol} /$ $\mathrm{m}^{3}$ with a standard deviation of $0.024 \mathrm{~mol} / \mathrm{m}^{3}$. As the mixing started with the mixing chamber filled with the $1 \mathrm{~mol} / \mathrm{m}^{3}$ fluid, the mixing performance or efficiency of the mixer can be estimated by the concentration shift towards $0.5 \mathrm{~mol} / \mathrm{m}^{3}$. Thus, the mixing efficiency of the mixer with $s=3 \mathrm{~mm}$ is estimated to be $15 \%$ better than the one with $s=0.75 \mathrm{~mm}$.

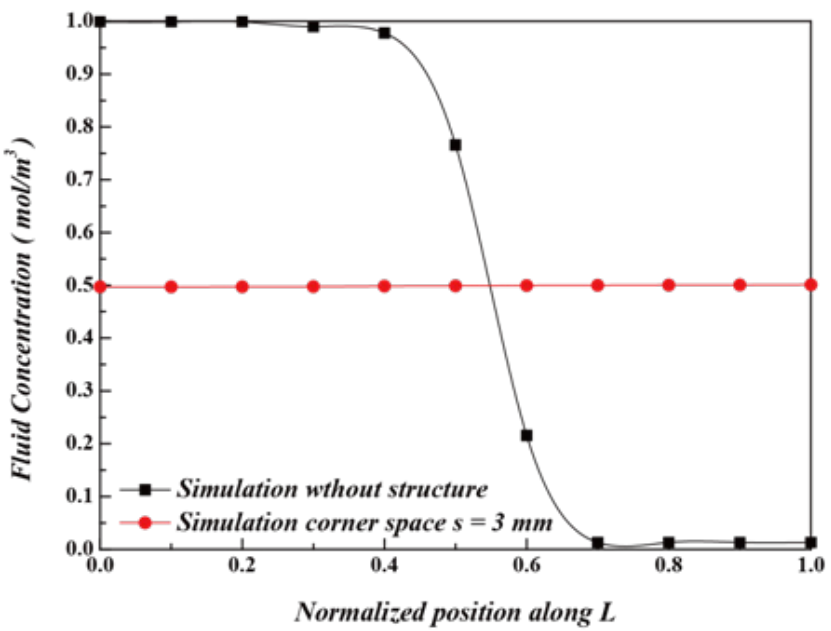

Figure 8 Outlet concentration distribution comparison of mixing chambers without a flow channel and with a flow channel $(s=3 \mathrm{~mm})$.

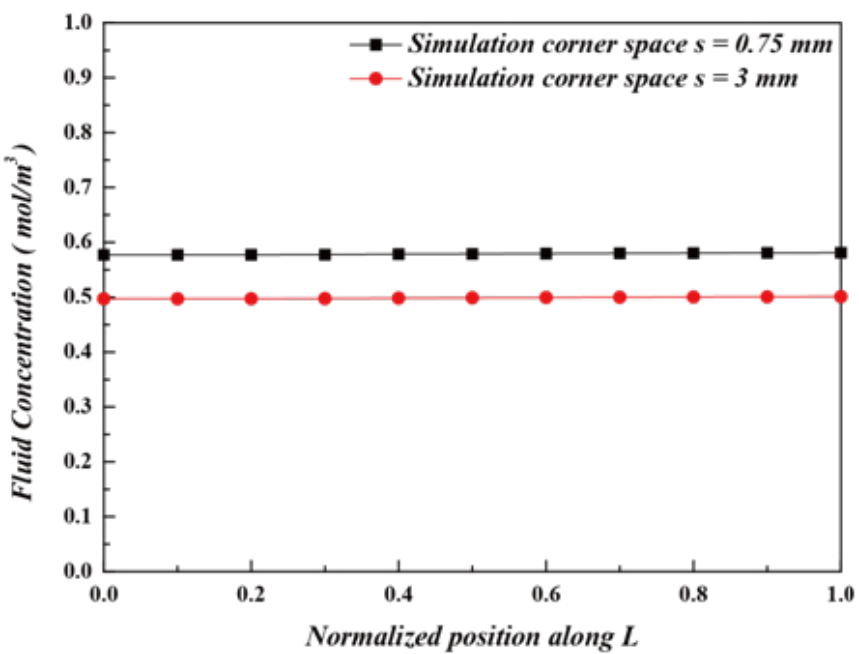

Figure 9 Outlet concentration comparison for different corner space designs.

Experimental evaluation of the mixer performance along the flow channel: The mixing efficiency for chambers with corner space $s=0.75 \mathrm{~mm}$ and $s=3 \mathrm{~mm}$ can be compared further through concentration monitoring at the 11 checkpoints along the flow channel towards the outlet. Figure 13 gives the fluid concentrations at these checkpoints. The locations of these checkpoints and concentration measurements are similar to the simulation results shown in Figure 7 \& Figure 10 \& Figure 13A-13D show the concentration distributions for mixing chambers with corner space $s=0.75 \mathrm{~mm}$ and $s=3 \mathrm{~mm}$. The chamber with $s=0.75 \mathrm{~mm}$ showed converging fluid concentration from Checkpoint 1 through Checkpoint 11 along the flow channel, but with $0.65 \mathrm{~mol} / \mathrm{m}^{3}$ at Checkpoint 11 and the outlet, suggesting that the mixing is partially complete. On the other hand, the mixing chamber with corner space $s=3 \mathrm{~mm}$ showed much better mixing performance than the one with corner space $s=0.75 \mathrm{~mm}$. A close-to-uniform $(\sim$ $\left.0.5 \mathrm{~mol} / \mathrm{m}^{3}\right)$ concentration distribution at the outlet was achieved. Due to the highly uniform concentration distribution at the outlet Figure $12 \mathrm{C}$, the mixer chamber with flow channel design and a corner space $s=3 \mathrm{~mm}$ was verified experimentally as a qualified mixer. Figure $14 \mathrm{~A}$ $\&$ Figure 14B demonstrate simulation and experimental fluid mixing, which used chambers with different corner spaces $s=0.75 \mathrm{~mm}$ and $s=3 \mathrm{~mm}$, respectively. Satisfactory mixing was achieved in 9 seconds by the mixing chamber structure with corner space $s=3 \mathrm{~mm}$, as shown in Figure 14B ; the chamber with $s=0.75 \mathrm{~mm}$ did not display complete mixing within the 9-sec timeframe. This comparison confirms the simulation prediction on the increased diffusion phenomenon in the larger corner space within the flow channel. These results demonstrate the capability and effectiveness of this miniature mixing system.

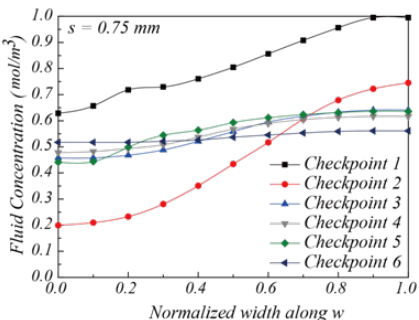

(A)

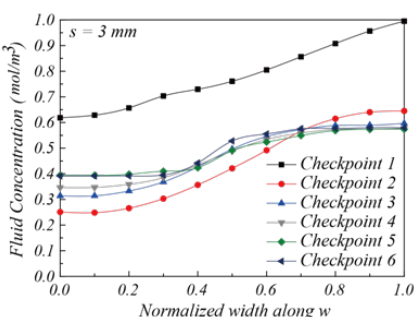

(C)

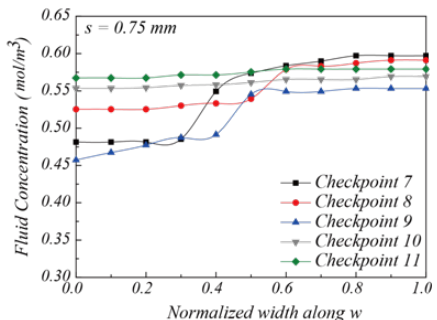

(B)

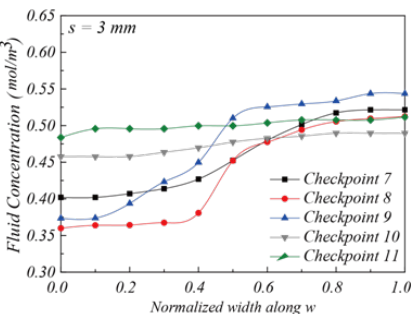

(D)
Figure 10 Simulated fluid concentration profile at II checkpoints: (A) $s=0.75 \mathrm{~mm}$, Checkpoints I-6; (B) $s=0.75 \mathrm{~mm}$, Checkpoints 7-I I; (C) $s=3 \mathrm{~mm}$ Checkpoints I-6; (D) $s=3 \mathrm{~mm}$, Checkpoints 7-II.

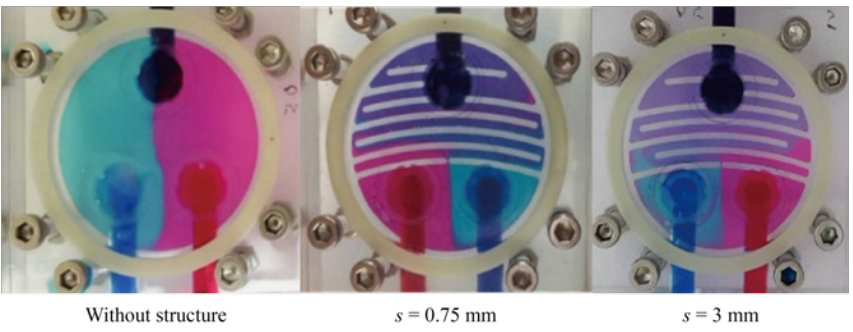

Figure I I Experiment measurement results (A) without mixing structure, $(B)$ $\mathrm{s}=0.75 \mathrm{~mm},(\mathrm{C}) \mathrm{s}=3 \mathrm{~mm}$.

Comparisons of the overall mixing performance of the simulation and experiment: To further compare the simulation results shown in Figure 10 and the experimental results shown in Figure13, the mixing performance parameters $M P$ Eq. (4) of the mixing chambers with different corner spaces were evaluated for both simulations and experiments, as shown in Figure 15 \& Figure 15A-15B represent the MP evaluation for corner space $s=0.75 \mathrm{~mm}$ and $s=3 \mathrm{~mm}$, respectively. The mixing performance of the mixing chamber with $s=3 \mathrm{~mm}$ is better 
than that with $s=0.75 \mathrm{~mm}$. There was minimal difference between the simulation and the experimental results due to the function loss not being estimated.
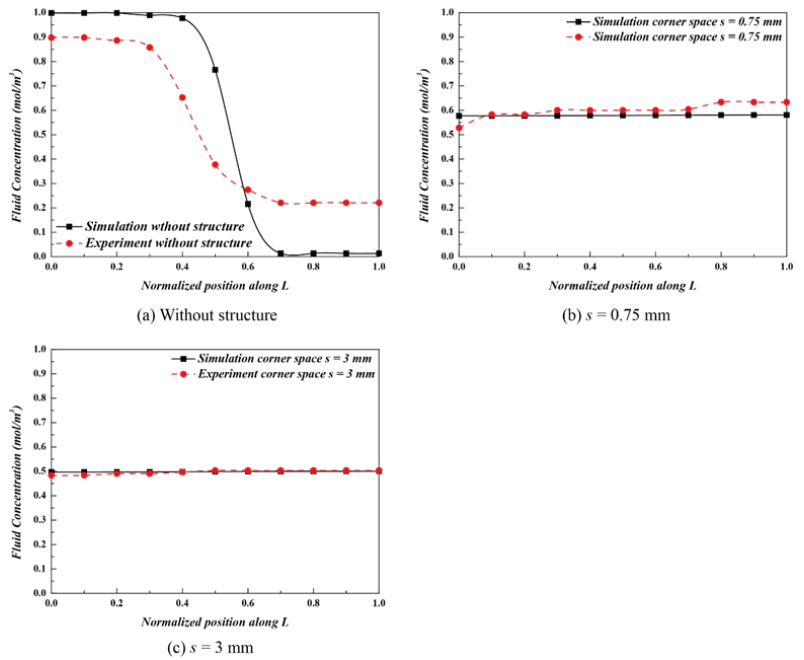

Figure 12 Comparison of simulation and experiment outlet (A) without structure outlet horizontal direction, (B) $s=0.75 \mathrm{~mm}$, (C) $s=3 \mathrm{~mm}$.

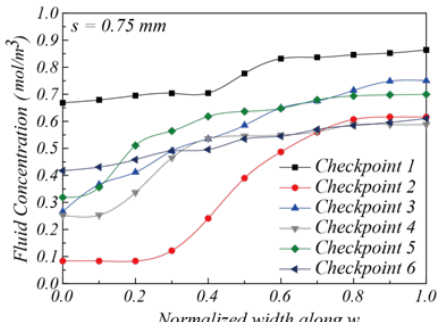

(A)

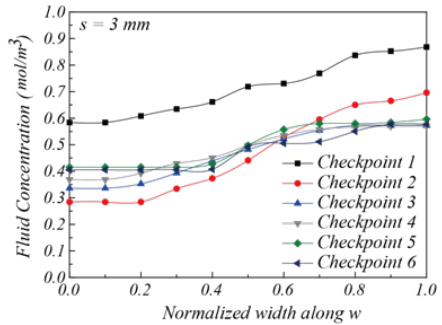

(C)

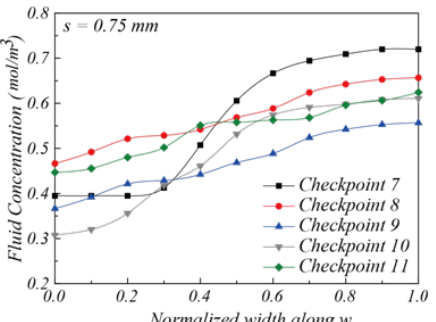

(B)

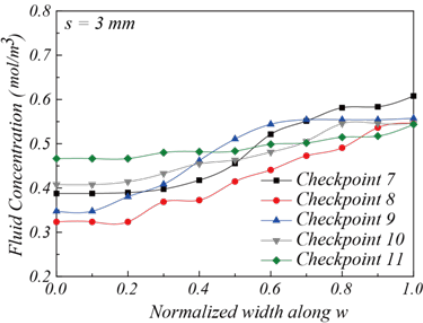

(D)

Figure 13 Measured fluid concentration profile at II checkpoints: (A) $s=0.75 \mathrm{~mm}$, Checkpoints I-6; (B) $s=0.75 \mathrm{~mm}$, Checkpoints 7-8; (C) $s=3 \mathrm{~mm}$, Checkpoints I-6; (D) s=3mm, Checkpoints 7-8.
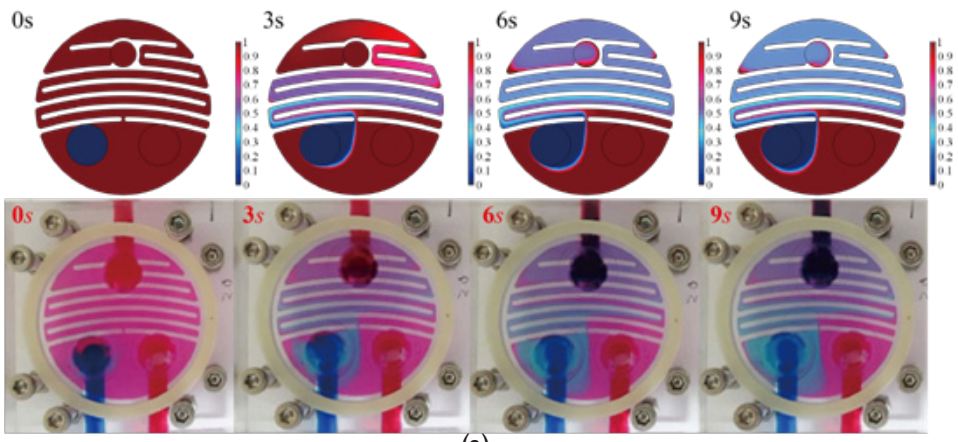

(a)
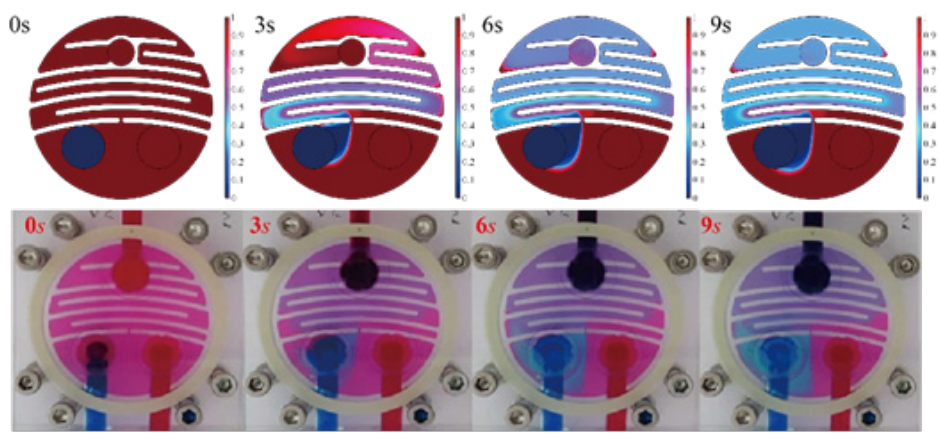

(b)

Figure 14 Time-lapse images $(t=0 \sim 9 \mathrm{sec})$ of the mixing chamber with corner space $(a) s=0.75 \mathrm{~mm},(B) s=3 \mathrm{~mm}$

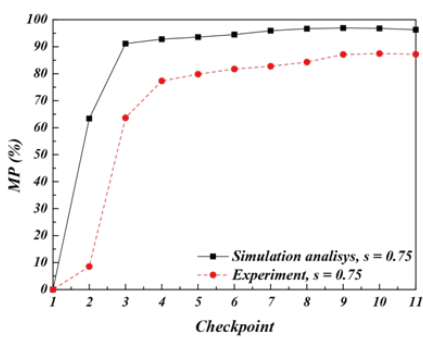

(a)

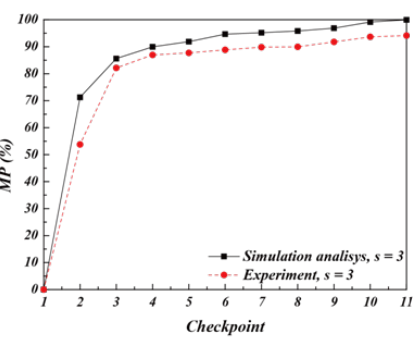

(b)

Figure 15 Comparison of the mixing performance of II checkpoints along the flow channel towards the outlet with (A) $s=0.75 \mathrm{~mm}$, (B) $s=3 \mathrm{~mm}$.

\section{Conclusion}

This study proposed a miniature mixing system made of PMMA that is disposable and can be assembled easily with two external pumps, such as the two piezoelectric pumps we developed and presented in a previous paper. ${ }^{35}$ Based on our simulation and experimental studies, we conclude our findings as follows. In determination of the diffusion coefficient of the dyed fluid, the study adopted the equation proposed by Galambos et al. ${ }^{40}$ The diffusion coefficient of the color dyes used in this paper was $1.5 \times 10-9 \mathrm{~m}^{2} / \mathrm{s}$, and it was used for mixer simulation. A good match between the simulation and experimental results was found. In a mixing chamber without channels, incomplete 
mixing resulted. This was due to the limited time for the two fluids to have contact and the mixing process being based only on diffusion. In contrast, by deploying serpentine channels $(\mathrm{s}=3 \mathrm{~mm})$ within the mixing chamber, a clear improvement can be seen, with the measured concentration close to $0.5 \mathrm{~mol} / \mathrm{m}^{3}$ at the outlet. Our studies suggest that a long flow channel length and appropriate corner spacing can yield highly satisfactory mixing performance. A mixing chamber with larger corner space $(\mathrm{s}=3 \mathrm{~mm})$ performed $15 \%$ better than one with smaller corner space $(\mathrm{s}=0.75 \mathrm{~mm})$, suggesting that the expansion of the turning corner spacing in the flow channel is positive for crossdiffusion between different dyed fluids. These results can provide guidelines for future mixer designs. This study used both simulations and experiments to examine the performance of the mixer system. Satisfactory mixing was achieved in 9 seconds, which is good for practical chemical and biomedical applications. Also, especially in the case of corner space $\mathrm{s}=3 \mathrm{~mm}$, the simulation successfully predicted the experimental results, suggesting that the parameter settings of the simulation can reflect real system conditions. This improves confidence in this study for simulation and design of more complicated fluidic systems. The simulation results were over predicted due to the emittance of function loss in the simulation. However, the trend of improved mixing along the flow channel in the case of corner space $\mathrm{s}=3 \mathrm{~mm}$ indeed showed a better result, with MP value reaching $93 \%$ at Checkpoint 11 in the experiment, as compared with the case of corner space $\mathrm{s}=0.75 \mathrm{~mm}$.

\section{Acknowledgements}

This research was funded by the Ministry of Economic Affairs, R.O.C. (103-EC-17-A-19-S1-225).

\section{Conflict of interest}

The author declares no conflict of interest.

\section{References}

1. Mizuno YC, Funakoshi M. Chaotic mixing due to a spatially periodic three-dimensional flow. Fluid Dyn Res. 2002;31:129-149.

2. Jeon MK, Kim JH, Noh J, et al. Design and characterization of a passive recycle micromixer. J Micromech Microeng. 2005;15:346.

3. Wong $\mathrm{SH}$, Ward $\mathrm{MC}$, Wharton $\mathrm{CW}$. Micro T-mixer as a rapid mixing micromixer. Sens Actuator B Chem. 2004;100(3):359-379.

4. Wang H, Iovenitti P, Harvey E, et al. Optimizing layout of obstacles for enhanced mixing in microchannels. Smart Mater Struct. 2002;11:662667.

5. Liu RH, Stremler MA, Sharp KV, et al. Passive mixing in a threedimensional serpentine microchannel, J. Micro-electromech Syst. 2000;9:190-197.

6. Park SJ, Kim JK, Park J, et al. Rapid three-dimensional passive rotation micromixer using the breakup process. J Micromech Microeng. 2004;14(1):6-14.

7. Yi M, Bau HH. The kinematics of bend-induced mixing in microconduits. J Heat Fluid Flow. 2003;24(5):645-656.

8. Lin Y, Gerfen GJ, Rousseau DL, et al. Ultrafast microfluidic mixer and freeze-quenching device. Anal Chem. 2003;75(20):5381-5386.

9. Yang J, Goto H, Matsumoto M, et al. Active micromixer for microfluidic systems using lead-zirconate-titanate (PZT)-generated ultrasonic vibration. Electrophoresis. 2000;21(1):116-119.
10. Lin JL, Lee $\mathrm{KH}$, Lee GB. Active mixing inside microchannels utilizing dynamic variation of gradient zeta potentials. Electrophoresis. 2005;26(24):4605-4615.

11. Niu $X$, Lee YK. Efficient spatial-temporal chaotic mixing in microchannels. J Micromech Microeng. 2003;13(3):454-462.

12. Tsouris C, Culbertson CT, De Paoli DW, et al. Electrohydrodynamic mixing in microchannels. AICHE J. 2003;49(8):2181-2186.

13. Glasgow I, Batton J, Aubry N. Electroosmotic mixing in microchannels. Lab Chip. 2004;4:558-562.

14. Sasaki N, Kitamori T, Kim HB. AC electroosmotic micromixer for chemical processing in a microchannel. Lab Chip. 2006;6(4):550-554.

15. Lee YK, Deval J, Tabeling P, et al. Chaotic mixing in electrokinetically and pressure driven micro flows. Microreaction Technology. 2001. p. $185-191$

16. Oddy MH, Santiago JG, Mikkelsen JC. Electrokinetic instability micromixing. Anal Chem. 2001;73(24):5822-5832.

17. Fu LM, Yang RJ, Lin $\mathrm{CH}$, et al. A novel microfluidic mixer utilizing electrokinetic driving forces under low switching frequency. Electrophoresis. 2005;26(9):1814-1824.

18. Chen $\mathrm{CH}$, Lin H, Lele SK, et al. Convective and absolute electrokinetic instability with conductivity gradients. J Fluid Mech. 2005;524:263-303.

19. Posner JD, Santiago JG. Convective instability of electrokinetic flows in a cross-shaped microchannel. J Fluid Mech. 2006;555:1-42.

20. Glasgow I, Aubry N. Enhancement of microfluidic mixing using time pulsing. Lab Chip. 2003;3(2):114-120.

21. El Moctar AO, Aubry N, Batton J. Electro-hydrodynamic micro-fluidic mixer. Lab chip. 2003;3(4):273-280.

22. Ahmed D, Mao X, Shi J, et al. A millisecond micromixer via singlebubble-based acoustic streaming. Lab chip. 2009;9:2738-2741.

23. Liu G, Yang X, Li Y, et al. Continuous flow controlled synthesis of gold nanoparticles using pulsed mixing microfluidic system. Adv Mater Sci Eng. 2015.11 p.

24. Hong CC, Choi JW, Ahn CH. A novel in-plane passive microfluidic mixer with modified Tesla structures. Lab Chip. 2004;4(2):109-113.

25. Mengeaud V, Josserand J, Girault HH. Mixing processes in a zigzag microchannel: finite element simulations and optical study. Anal Chem 2002;74(16):4279-4286.

26. Schwesinger N, Frank T, Wurmus H. A modular microfluid system with an integrated micromixer. J Micromech Microeng. 1996;6(1):99.

27. Johnson TJ, Ross D, Locascio LE. Rapid microfluidic mixing. Anal Chem. 2002;74(1):45-51

28. Jiang F, Drese KS, Hardt S, et al. Helical flows and chaotic mixing in curved micro channels. AIChE journal. 2004;50(9):2297-2305.

29. Sheu TS, Chen SJ, Chen JJ. Mixing of a split and recombine micromixer with tapered curved microchannels. Chemical engineering science. 2012;71:321-332.

30. Schönfeld F, Hessel V, Hofmann C. An optimised split-and-recombine micro-mixer with uniform chaotic mixing. Lab chip. 2004;4:65-69.

31. Li L, Lee LJ, Castro JM, et al. Improving mixing efficiency of a polymer micromixer by use of a plastic shim divider. J Micromech Microeng. 2010;20(3):35-42.

32. Lynn NS, Dandy DS. Geometrical optimization of helical flow in grooved micromixers. Lab chip. 2007;7:580-587. 
33. Nguyen NT, Wu Z. Micromixers-a review. J Micromech. Microeng. 2005;15(2):R1-15.

34. Jeong GS, Chung S, Kim CB, et al. Applications of micromixing technology. 2010;135(3):460-473.

35. Ma HK, Chen RH, Hsu YH. Development of a piezoelectric-driven miniature pump for biomedical applications. Sens. Actuator A-Phys. 2015;234:23-33.

36. Pradeep A, Raveendran J, Ramachandran T, et al. Computational simulation and fabrication of smooth edged passive micromixers with alternately varying diameter for efficient mixing. Microelectron Eng. 2016;165:32-40.
37. Sayah A, Gijs MA. Understanding the mixing process in 3D microfluidic nozzle/diffuser systems: simulations and experiments. J Micromech. Microeng. 2016;26:115017.

38. Ansari MA, Kim KY, Anwar K, et al. A novel passive micromixer based on unbalanced splits and collisions of fluid streams. J Micromech. Microeng. 2010;20(5):055007.

39. Afzal A, Kim KY. Passive split and recombination micromixer with convergent-divergent walls. Chem Eng J. 2012;203:182-192.

40. Galambos P, Forster FK. Micro Total Analysis Systems. In: Harrison, D Jed, et al. editors. Proceedings of the uTAS Workshop, Canada, Netherlands: Springer; 1998. 492 p. 